\section{Motivation rubs off on patients}

I am very proud to be a team member of our well established and respected practice. I have been working at my practice for many years and have recently achieved my certificate in oral health education. As we have a very busy, well organised, but relaxed general practice, I have taken on the role of identifying our patients' oral health needs. For example, ensuring dietary advice given to our patients is consistent with general healthy eating guidelines.

I understand that many factors can influence the ability to motivate patients so from experience I feel that the information provided should be clear and understandable resulting in client satisfaction. Most importantly I never feel disillusioned or want to stop giving advice as progress can be slow. As they progress I give them positive feedback which encourages further progress.

\section{Paula Reid, receptionist and oral health educator, Co. Antrim, N. Ireland \\ Reality check?}

May I please have the opportunity to reply to Margaret Ross's letter (Summer 05, Star Letter).

The comparisons she makes between the world of dentistry and medicine in their use of complementary professions is sound in theory but in practice is wholly inappropriate.

The ratio of oral health practitioners (as she describes them) to dentists is very very small whereas the ratio of nurses to doctors is very high, therefore for there to be any real expectation of real impact on our current problems is ridiculous.

I should also like to take this opportunity to express concern that, laudable as they are, any preoccupation with career development and expansion of any of the dental team is a distraction from the real need for improving oral health with the resources we have now.

\section{R. J. Burrows}

Dentist, Isle of Wight

\section{ANOTHER WAY FORWARD}

On behalf of Dave Martin, (Summer 05, Let me climb the career ladder), I do not think it would be possible to bypass the required number of academic units for entry to a dental degree course, despite even exceptional practical skills. However, as a possibility I have extracted some useful information from the University of Wales website regarding their entry requirements. In view of Mr Martin's experience, I wondered whether this may be an appropriate way forward:

\section{B. 11 BTEC QUALIFICATIONS}

Applicants taking the National Diploma Course in Science or Medical Laboratory Science would be considered for entry to the Foundation (six-year) Programme, A204. A typical offer would be for five Distinctions to be obtained in relevant Final Year Units, with Merit achieved in the remaining units.

\section{B.3 PROGRAMME A204 - FOUNDATION YEAR DENTISTRY, (YEAR 0), (6-YEAR PROGRAMME)}

The Foundation year is designed for applicants who have demonstrated a high academic potential but who have not been afforded the opportunity of meeting the subject requirements for direct entry to
SEND YOUR LETTERS to: the Editor, Vital Magazine, BDJ, Nature Publishing Group, 4-6 Crinan Street, London NI 9XW or email vitaleditorial@nature.com. Authors must sign the letter, which may be edited for reasons of space.

Our star letter writer will receive a collection of the latest Colgate Oral Health Professional products ( courtesy of Colgate.

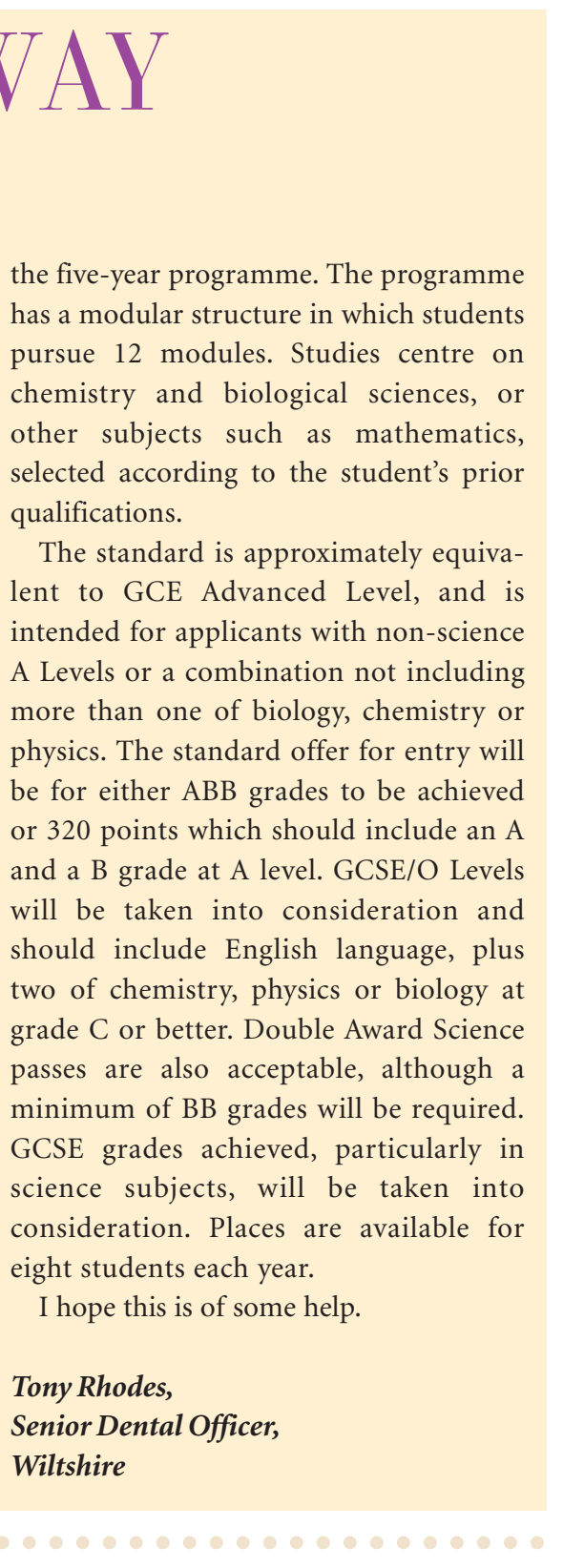

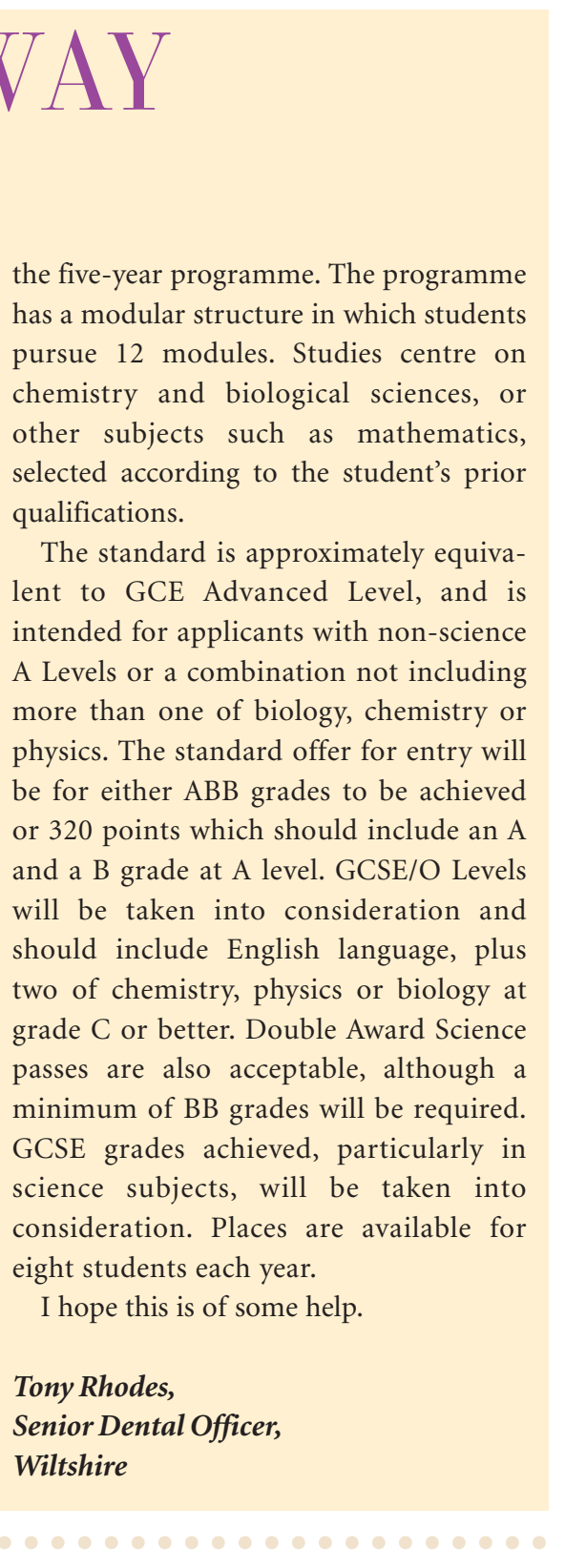 \\ The
the five-year programme. The programme
has a modular structure in which students
pursue 12 modules. Studies centre on
chemistry and biological sciences, or
other subjects such as mathematics,
selected according to the student's prior
qualifications.
The standard is approximately equiva-
lent to GCE Advanced Level, and is
intended for applicants with non-science
A Levels or a combination not including
more than one of biology, chemistry or
physics. The standard offer for entry will
be for either ABB grades to be achieved
or 320 points which should include an A
and a B grade at A level. GCSE/O Levels
will be taken into consideration and
should include English language, plus
two of chemistry, physics or biology at
grade C or better. Double Award Science
passes are also acceptable, although a
minimum of BB grades will be required.
GCSE grades achieved, particularly in
science subjects, will be taken into
consideration. Places are available for
eight students each year.
I hope this is of some help.
Tenter,

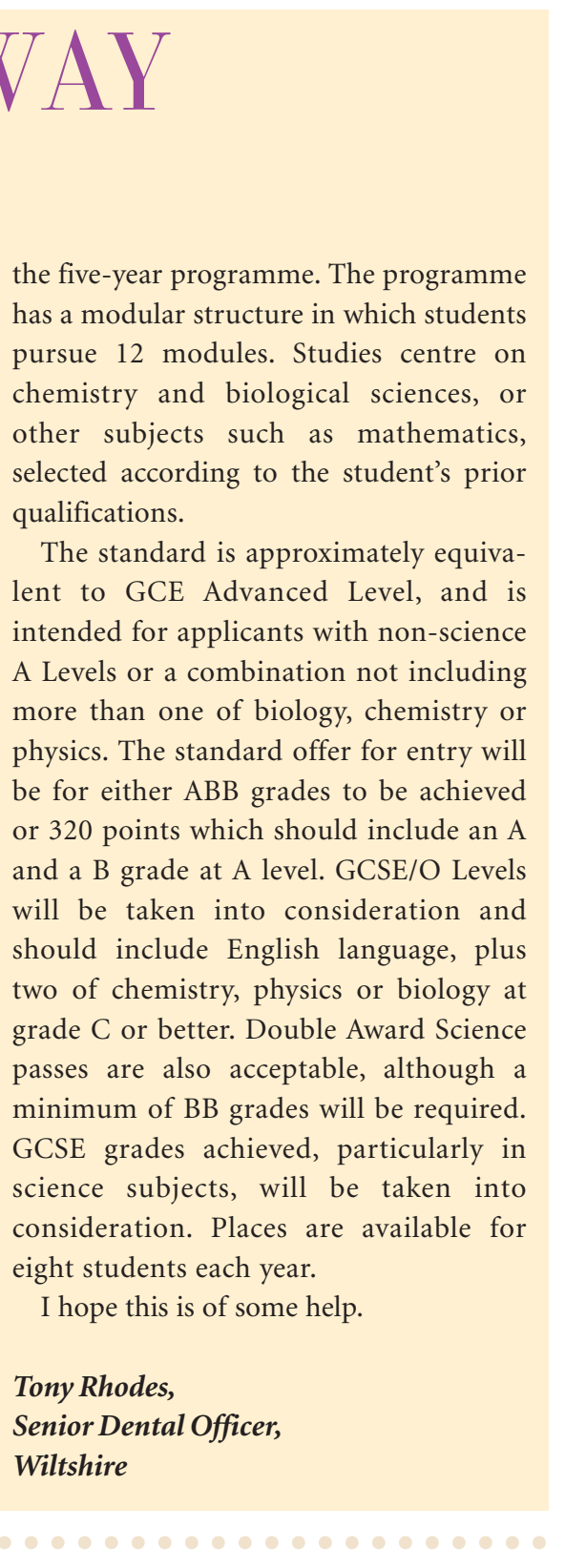

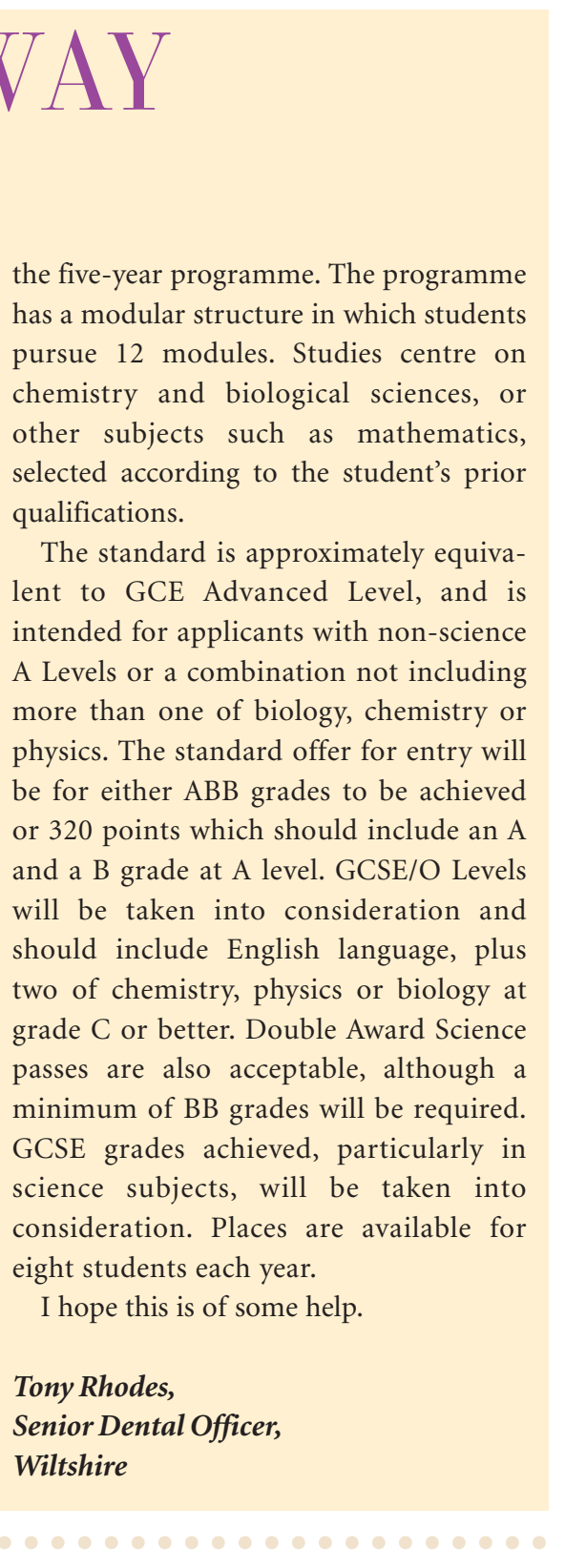

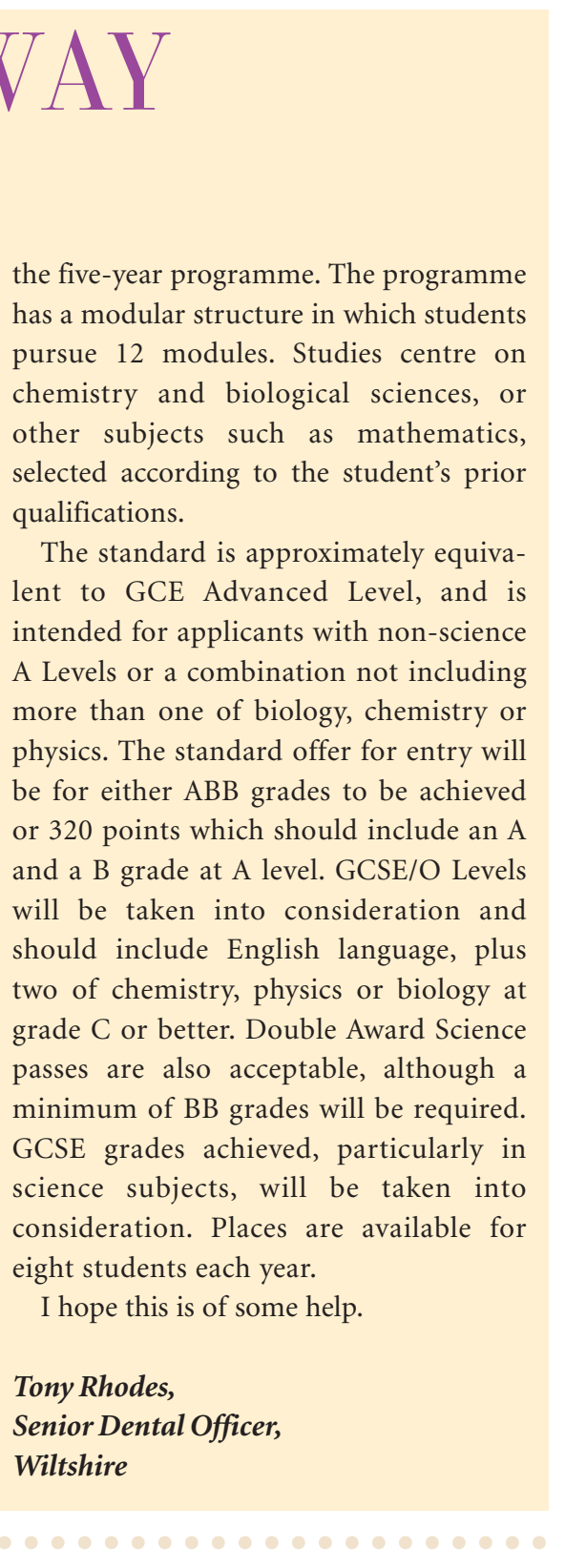 \\ The five-year programme. The programme
has a modular structure in which students
pursue 12 modules. Studies centre on
chemistry and biological sciences, or
other subjects such as mathematics,
selected according to the student's prior
qualifications.
The standard is approximately equiva-
lent to GCE Advanced Level, and is
intended for applicants with non-science
A Levels or a combination not including
more than one of biology, chemistry or
physics. The standard offer for entry will
be for either ABB grades to be achieved
or 320 points which should include an A
and a B grade at A level. GCSE/O Levels
will be taken into consideration and
should include English language, plus
two of chemistry, physics or biology at
grade C or better. Double Award Science
passes are also acceptable, although a
minimum of BB grades will be required.
GCSE grades achieved, particularly in
science subjects, will be taken into
consideration. Places are available for
eight students each year.
I hope this is of some help.
Tenticer,
two

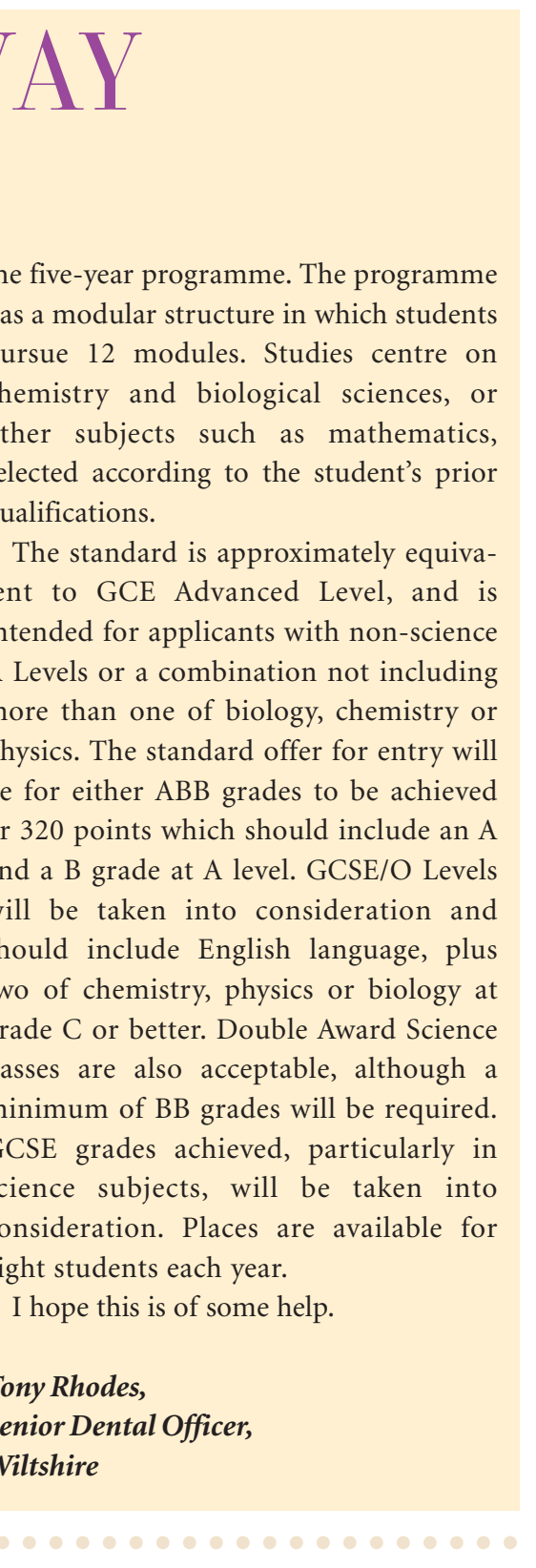

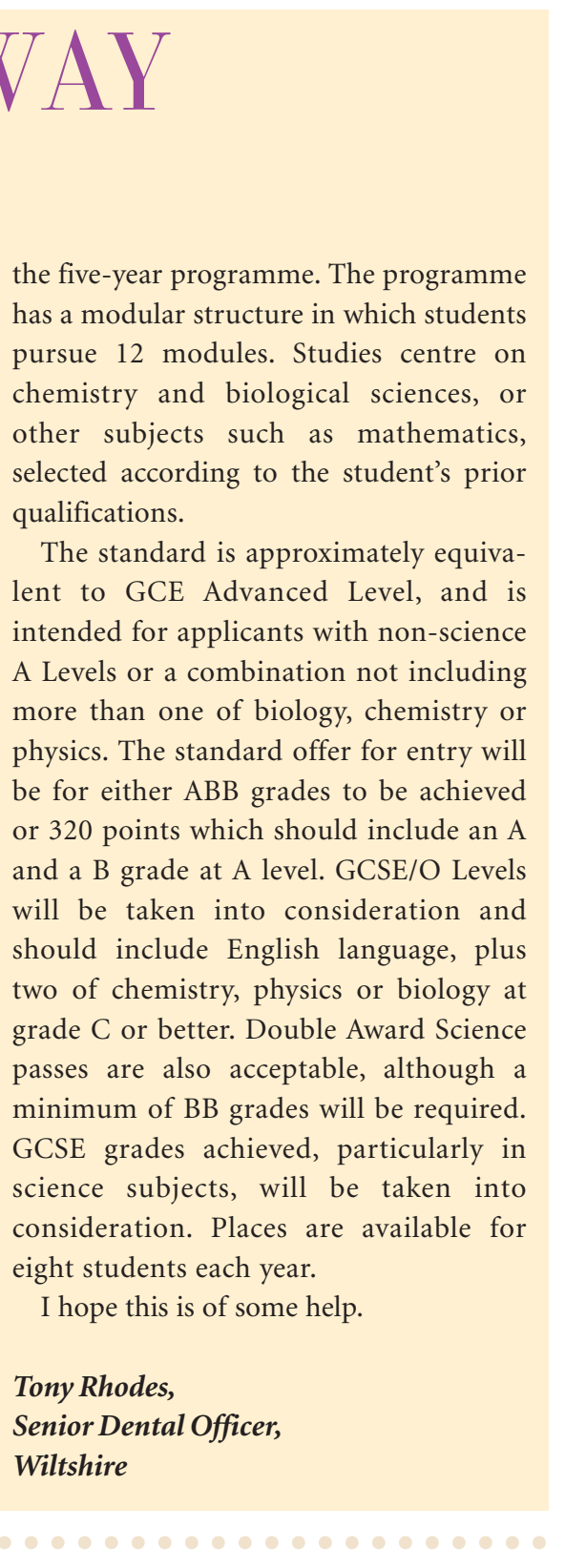

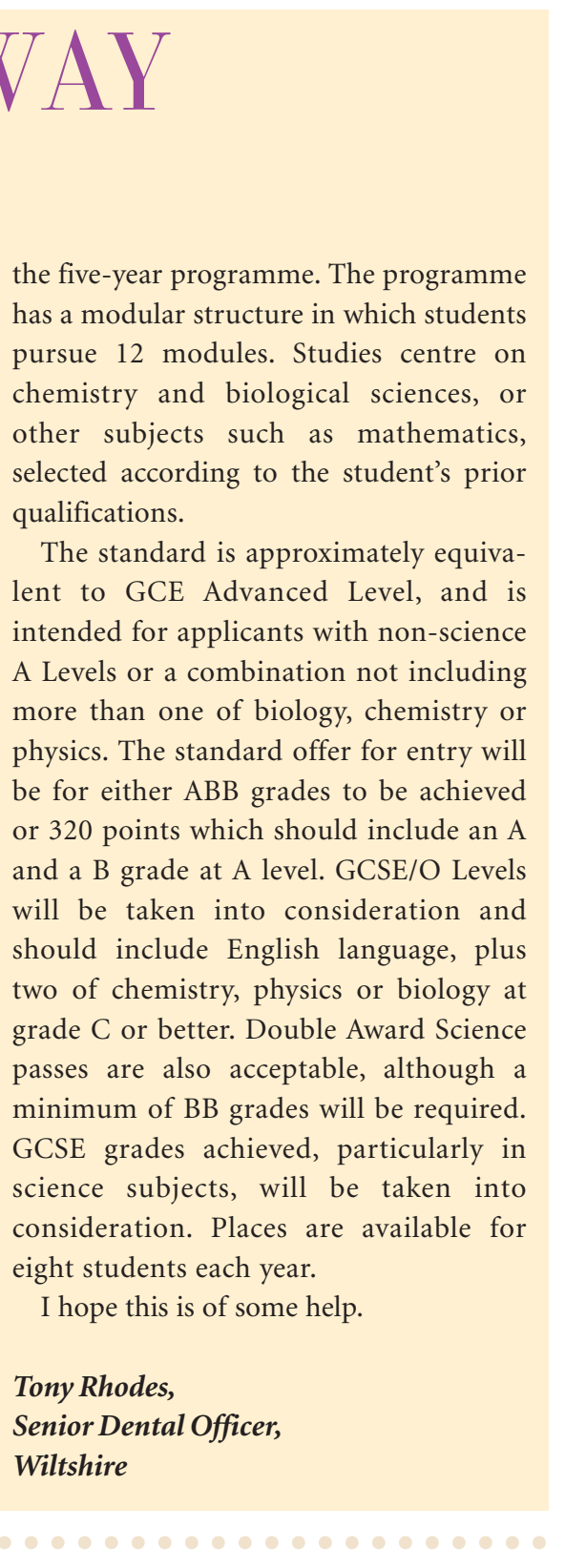 \\ The
the five-year programme. The programme
has a modular structure in which students
pursue 12 modules. Studies centre on
chemistry and biological sciences, or
other subjects such as mathematics,
selected according to the student's prior
qualifications.
The standard is approximately equiva-
lent to GCE Advanced Level, and is
intended for applicants with non-science
A Levels or a combination not including
more than one of biology, chemistry or
physics. The standard offer for entry will
be for either ABB grades to be achieved
or 320 points which should include an A
and a B grade at A level. GCSE/O Levels
will be taken into consideration and
should include English language, plus
two of chemistry, physics or biology at
grade C or better. Double Award Science
passes are also acceptable, although a
minimum of BB grades will be required.
GCSE grades achieved, particularly in
science subjects, will be taken into
consideration. Places are available for
eight students each year.
I hope this is of some help.
Tenter,

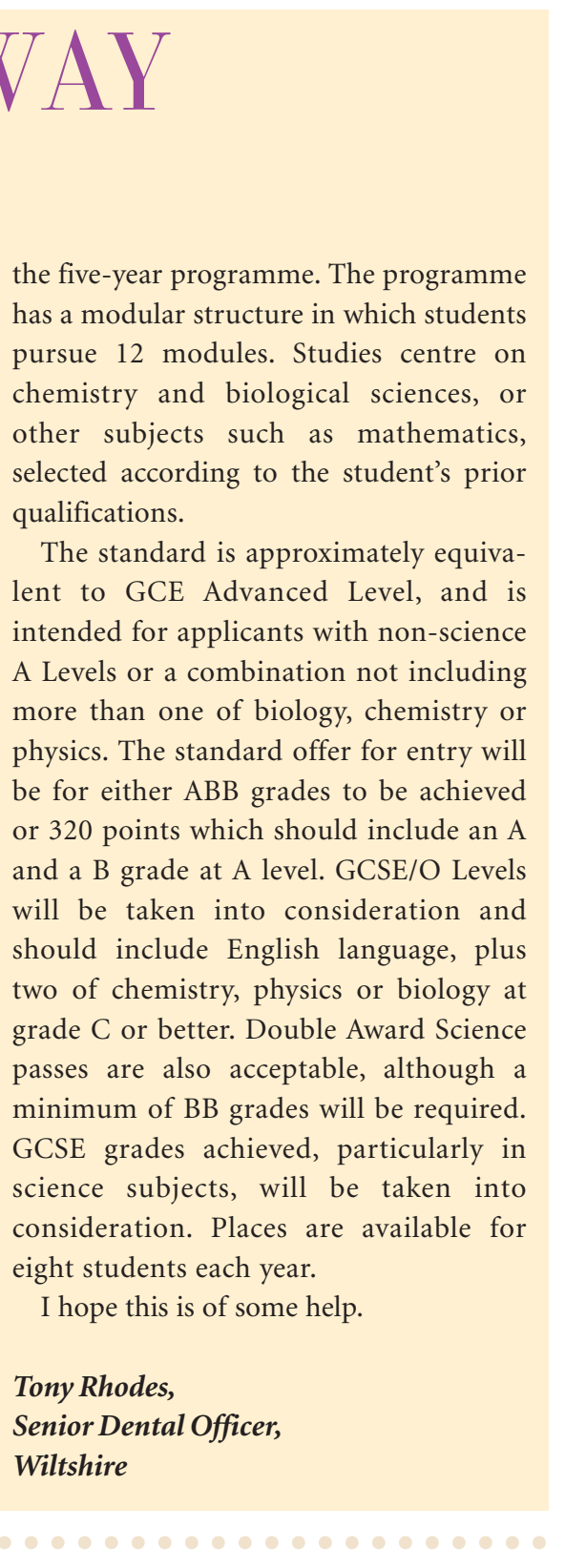 \\ The
the five-year programme. The programme
has a modular structure in which students
pursue 12 modules. Studies centre on
chemistry and biological sciences, or
other subjects such as mathematics,
selected according to the student's prior
qualifications.
The standard is approximately equiva-
lent to GCE Advanced Level, and is
intended for applicants with non-science
A Levels or a combination not including
more than one of biology, chemistry or
physics. The standard offer for entry will
be for either ABB grades to be achieved
or 320 points which should include an A
and a B grade at A level. GCSE/O Levels
will be taken into consideration and
should include English language, plus
two of chemistry, physics or biology at
grade C or better. Double Award Science
passes are also acceptable, although a
minimum of BB grades will be required.
GCSE grades achieved, particularly in
science subjects, will be taken into
consideration. Places are available for
eight students each year.
I hope this is of some help.
Tenter, \\ The
the five-year programme. The programme
has a modular structure in which students
pursue 12 modules. Studies centre on
chemistry and biological sciences, or
other subjects such as mathematics,
selected according to the student's prior
qualifications.
The standard is approximately equiva-
lent to GCE Advanced Level, and is
intended for applicants with non-science
A Levels or a combination not including
more than one of biology, chemistry or
physics. The standard offer for entry will
be for either ABB grades to be achieved
or 320 points which should include an A
and a B grade at A level. GCSE/O Levels
will be taken into consideration and
should include English language, plus
two of chemistry, physics or biology at
grade C or better. Double Award Science
passes are also acceptable, although a
minimum of BB grades will be required.
GCSE grades achieved, particularly in
science subjects, will be taken into
consideration. Places are available for
eight students each year.
I hope this is of some help.
Tenter,

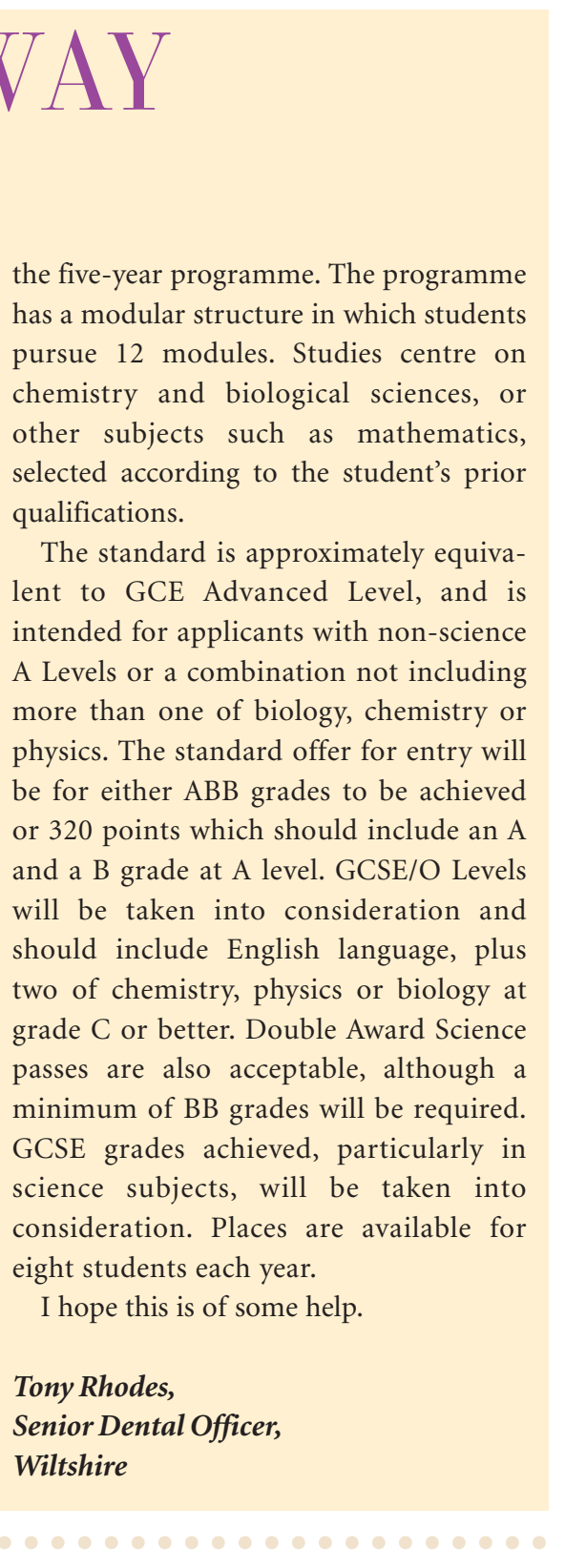

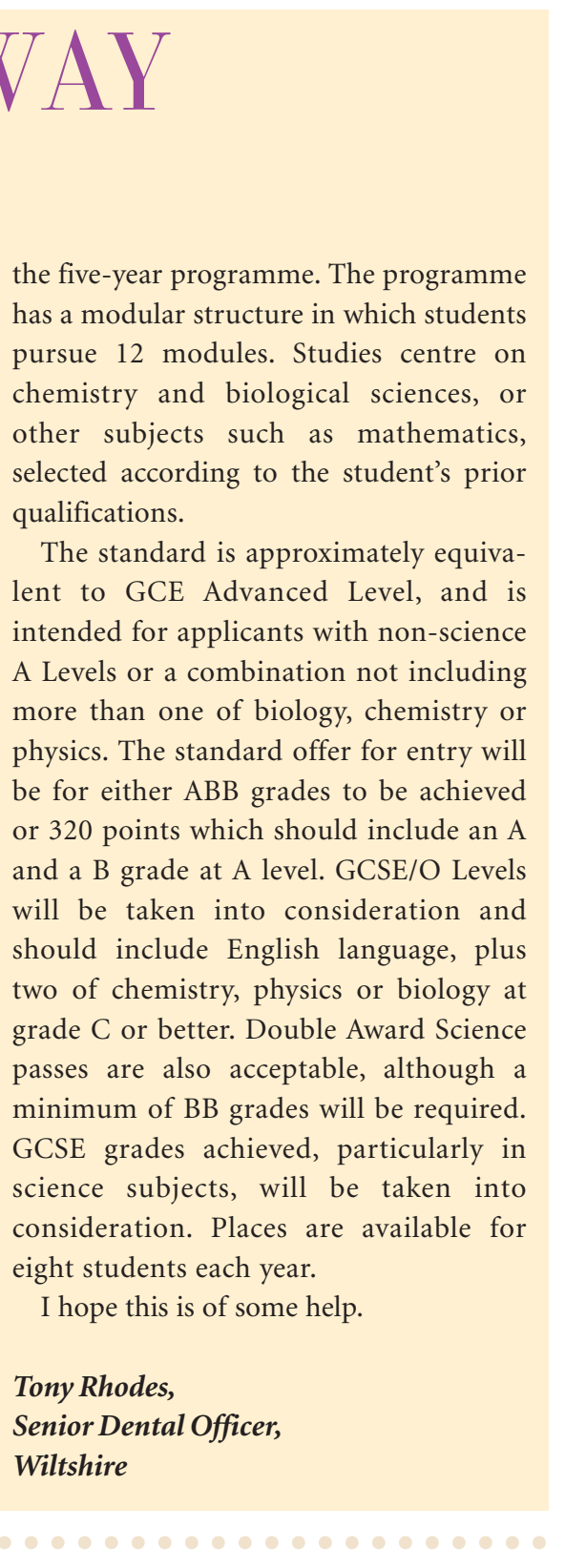 \\ The
the five-year programme. The programme
has a modular structure in which students
pursue 12 modules. Studies centre on
chemistry and biological sciences, or
other subjects such as mathematics,
selected according to the student's prior
qualifications.
The standard is approximately equiva-
lent to GCE Advanced Level, and is
intended for applicants with non-science
A Levels or a combination not including
more than one of biology, chemistry or
physics. The standard offer for entry will
be for either ABB grades to be achieved
or 320 points which should include an A
and a B grade at A level. GCSE/O Levels
will be taken into consideration and
should include English language, plus
two of chemistry, physics or biology at
grade C or better. Double Award Science
passes are also acceptable, although a
minimum of BB grades will be required.
GCSE grades achieved, particularly in
science subjects, will be taken into
consideration. Places are available for
eight students each year.
I hope this is of some help.
Tenter,

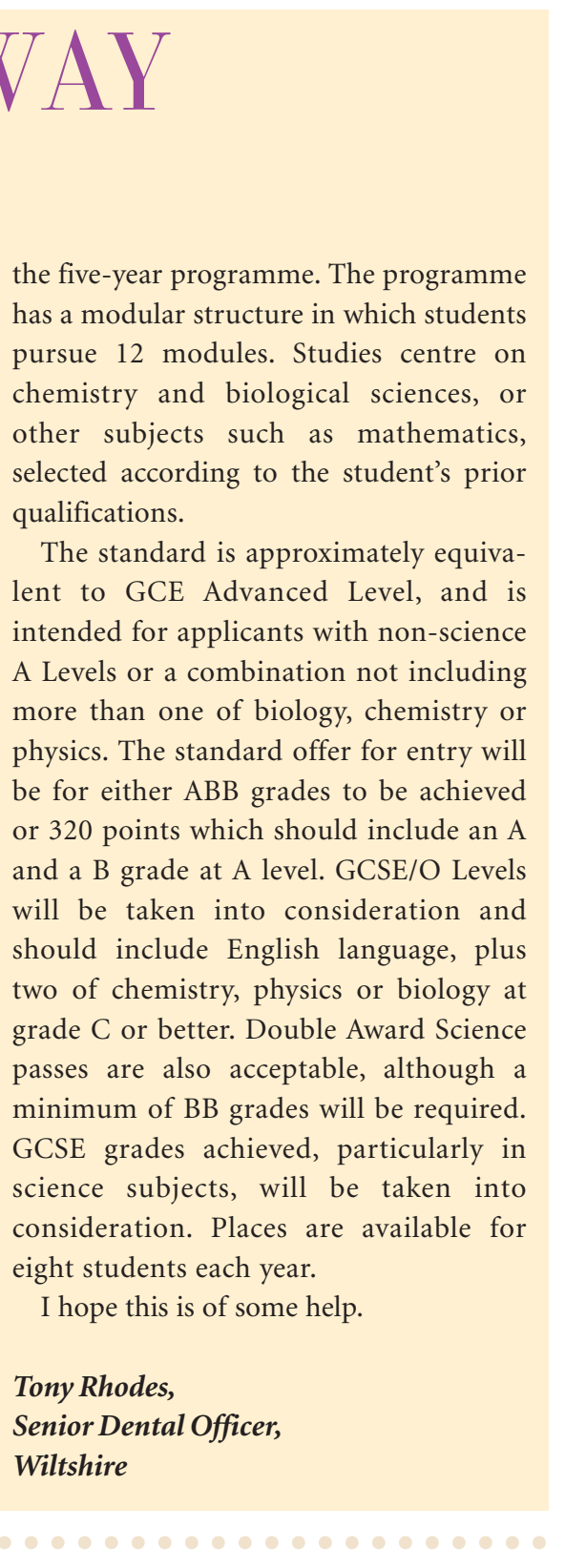

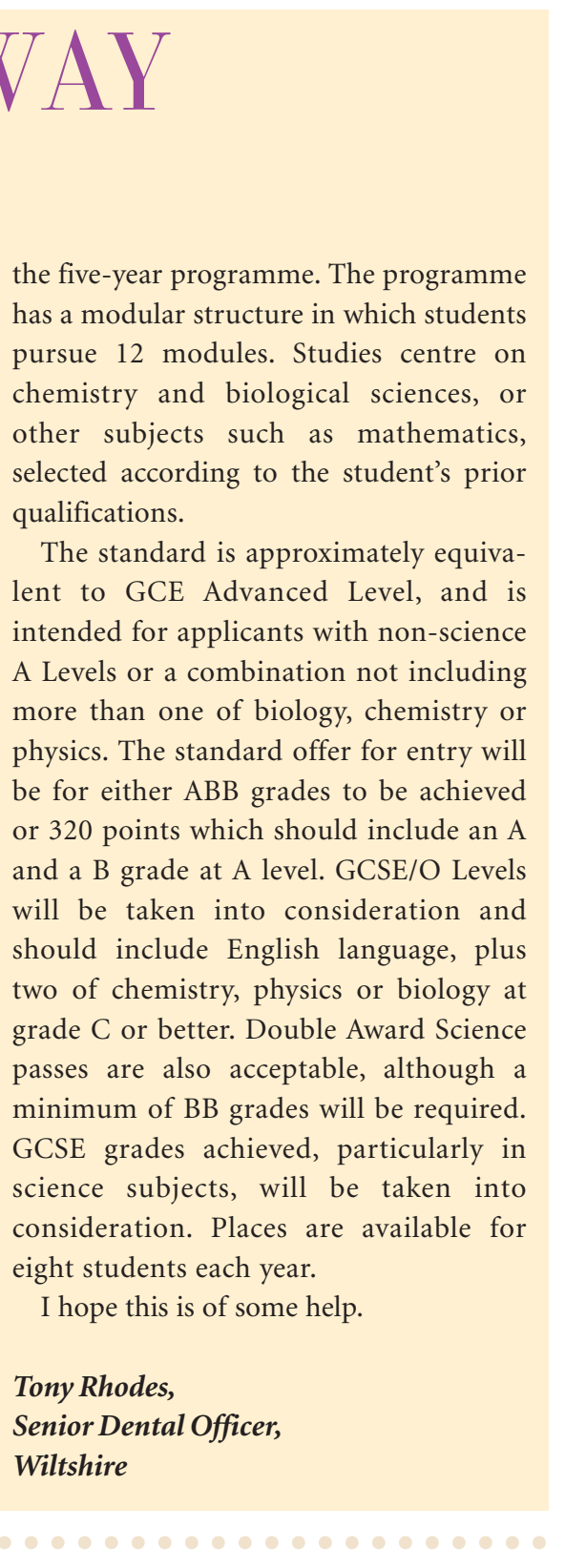

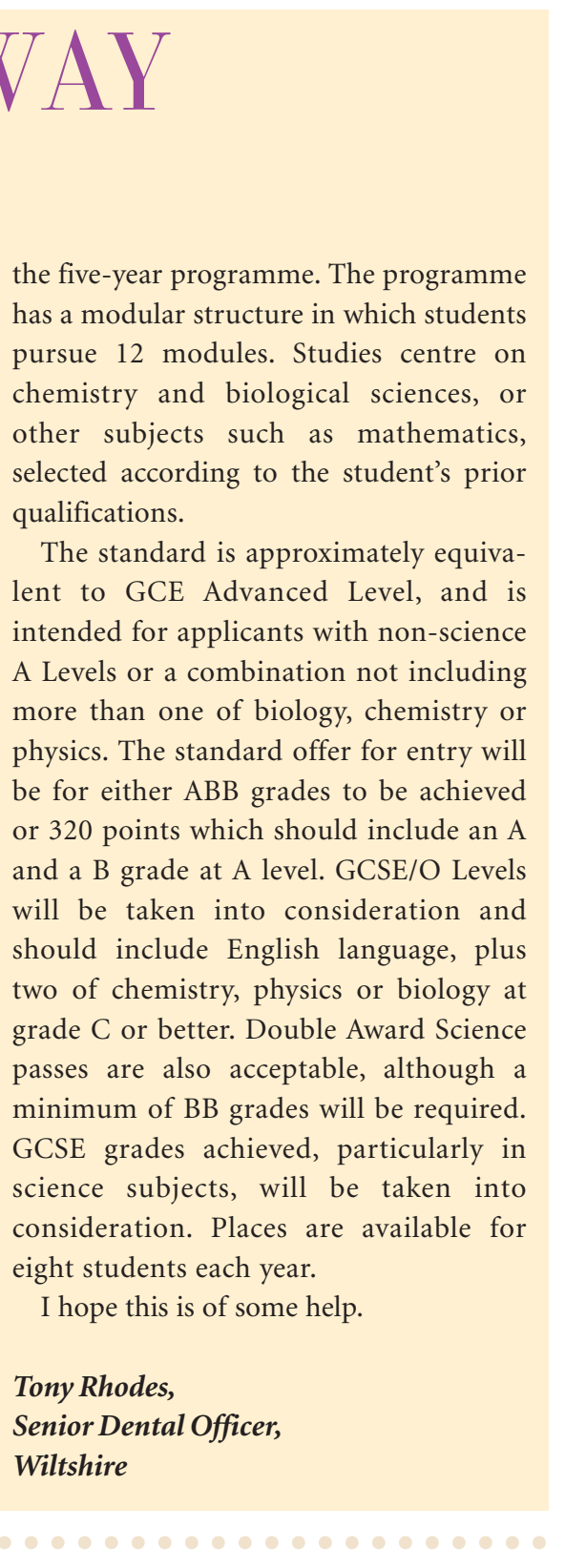

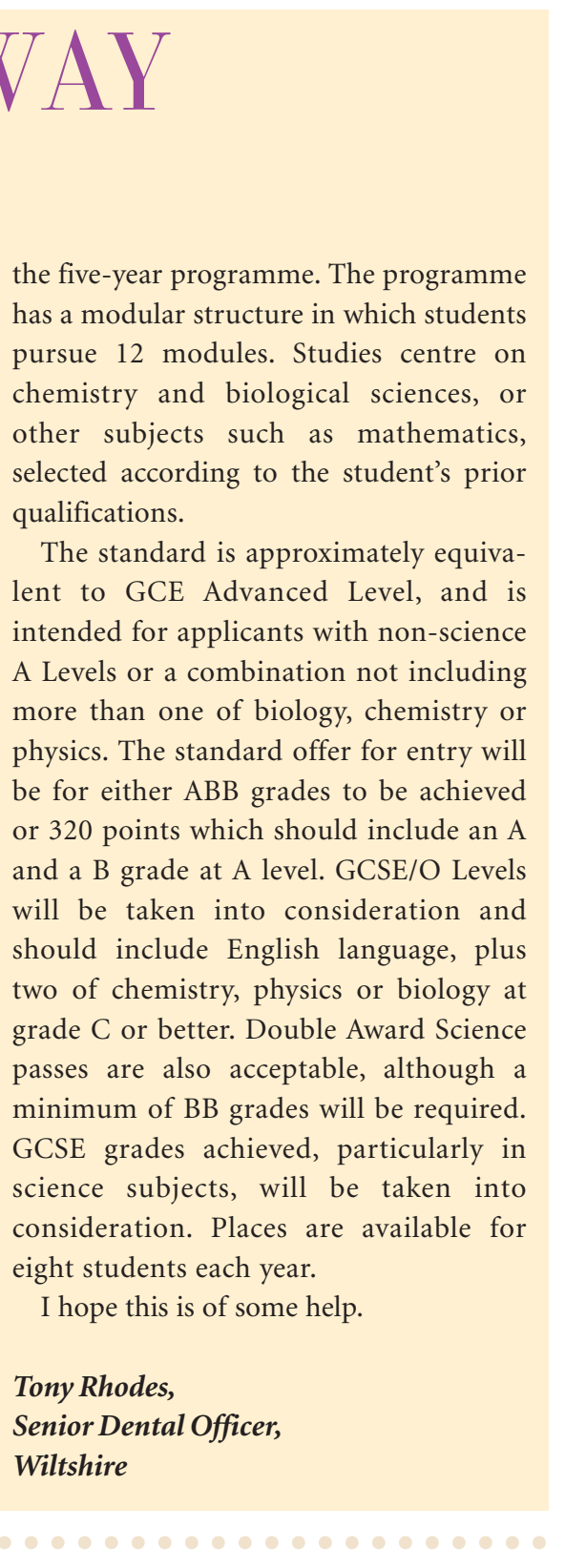 \\ The
the five-year programme. The programme
has a modular structure in which students
pursue 12 modules. Studies centre on
chemistry and biological sciences, or
other subjects such as mathematics,
selected according to the student's prior
qualifications.
The standard is approximately equiva-
lent to GCE Advanced Level, and is
intended for applicants with non-science
A Levels or a combination not including
more than one of biology, chemistry or
physics. The standard offer for entry will
be for either ABB grades to be achieved
or 320 points which should include an A
and a B grade at A level. GCSE/O Levels
will be taken into consideration and
should include English language, plus
two of chemistry, physics or biology at
grade C or better. Double Award Science
passes are also acceptable, although a
minimum of BB grades will be required.
GCSE grades achieved, particularly in
science subjects, will be taken into
consideration. Places are available for
eight students each year.
I hope this is of some help.
Tenter, \\ The
the five-year programme. The programme
has a modular structure in which students
pursue 12 modules. Studies centre on
chemistry and biological sciences, or
other subjects such as mathematics,
selected according to the student's prior
qualifications.
The standard is approximately equiva-
lent to GCE Advanced Level, and is
intended for applicants with non-science
A Levels or a combination not including
more than one of biology, chemistry or
physics. The standard offer for entry will
be for either ABB grades to be achieved
or 320 points which should include an A
and a B grade at A level. GCSE/O Levels
will be taken into consideration and
should include English language, plus
two of chemistry, physics or biology at
grade C or better. Double Award Science
passes are also acceptable, although a
minimum of BB grades will be required.
GCSE grades achieved, particularly in
science subjects, will be taken into
consideration. Places are available for
eight students each year.
I hope this is of some help.
Tenter, \\ The
the five-year programme. The programme
has a modular structure in which students
pursue 12 modules. Studies centre on
chemistry and biological sciences, or
other subjects such as mathematics,
selected according to the student's prior
qualifications.
The standard is approximately equiva-
lent to GCE Advanced Level, and is
intended for applicants with non-science
A Levels or a combination not including
more than one of biology, chemistry or
physics. The standard offer for entry will
be for either ABB grades to be achieved
or 320 points which should include an A
and a B grade at A level. GCSE/O Levels
will be taken into consideration and
should include English language, plus
two of chemistry, physics or biology at
grade C or better. Double Award Science
passes are also acceptable, although a
minimum of BB grades will be required.
GCSE grades achieved, particularly in
science subjects, will be taken into
consideration. Places are available for
eight students each year.
I hope this is of some help.
Tenter,

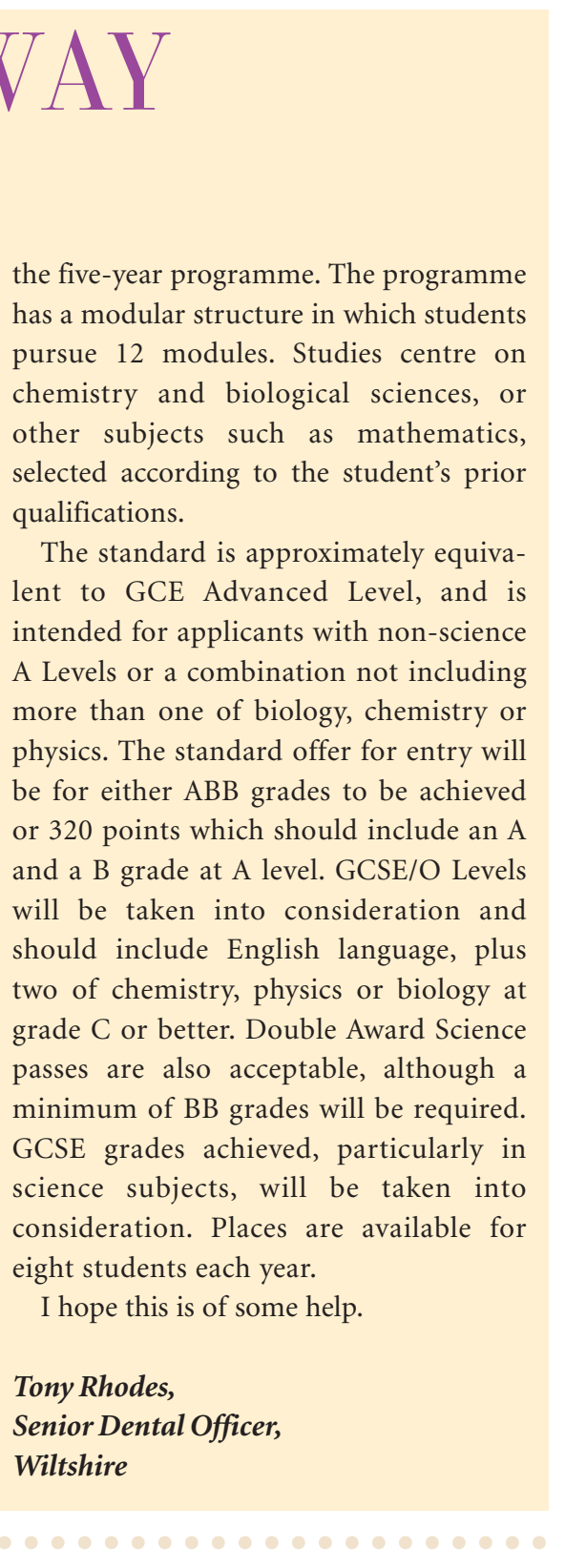

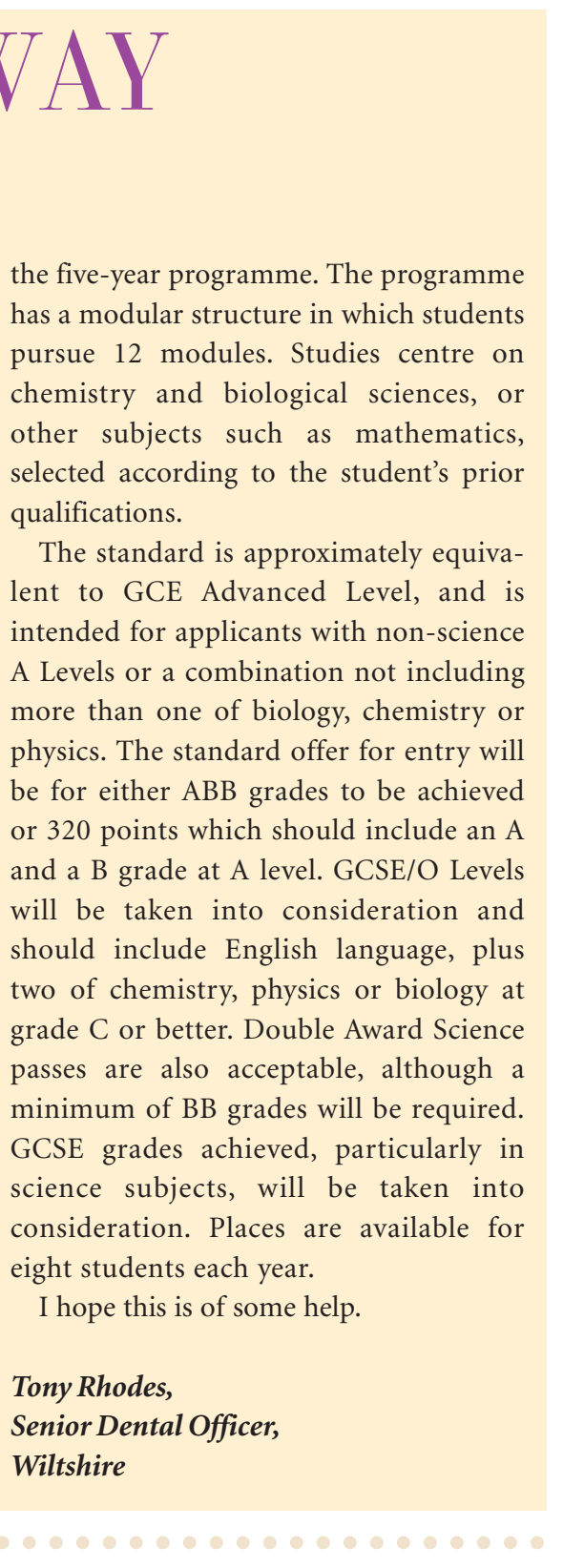 \\ The
he five-year programme. The programme
has a modular structure in which students
pursue 12 modules. Studies centre on
hemistry and biological sciences, or
ther subjects such as mathematics,
elected according to the student's prior
qualifications.
The standard is approximately equiva-
ent to GCE Advanced Level, and is
ntended for applicants with non-science
A Levels or a combination not including
more than one of biology, chemistry or
physics. The standard offer for entry will
be for either ABB grades to be achieved
Oenior Dental Officer,
I 320 points which should include an A
nd a B grade at A level. GCSE/O Levels
will be taken into consideration and
hould include English language, plus
wo of chemistry, physics or biology at
grade C or better. Double Award Science
passes are also acceptable, although a
minimum of BB grades will be required.
GCSE grades achieved, particularly in
cience subjects, will be taken into
onsideration. Places are available for
ight students each year.
I home help.

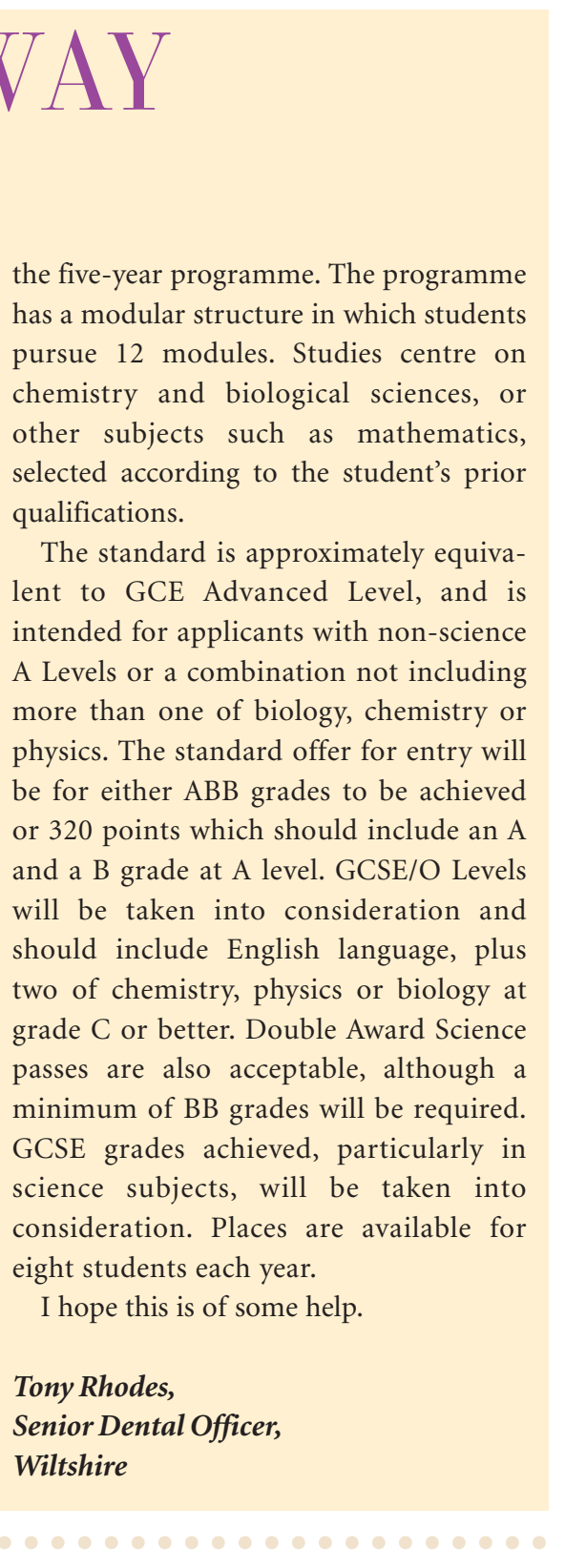

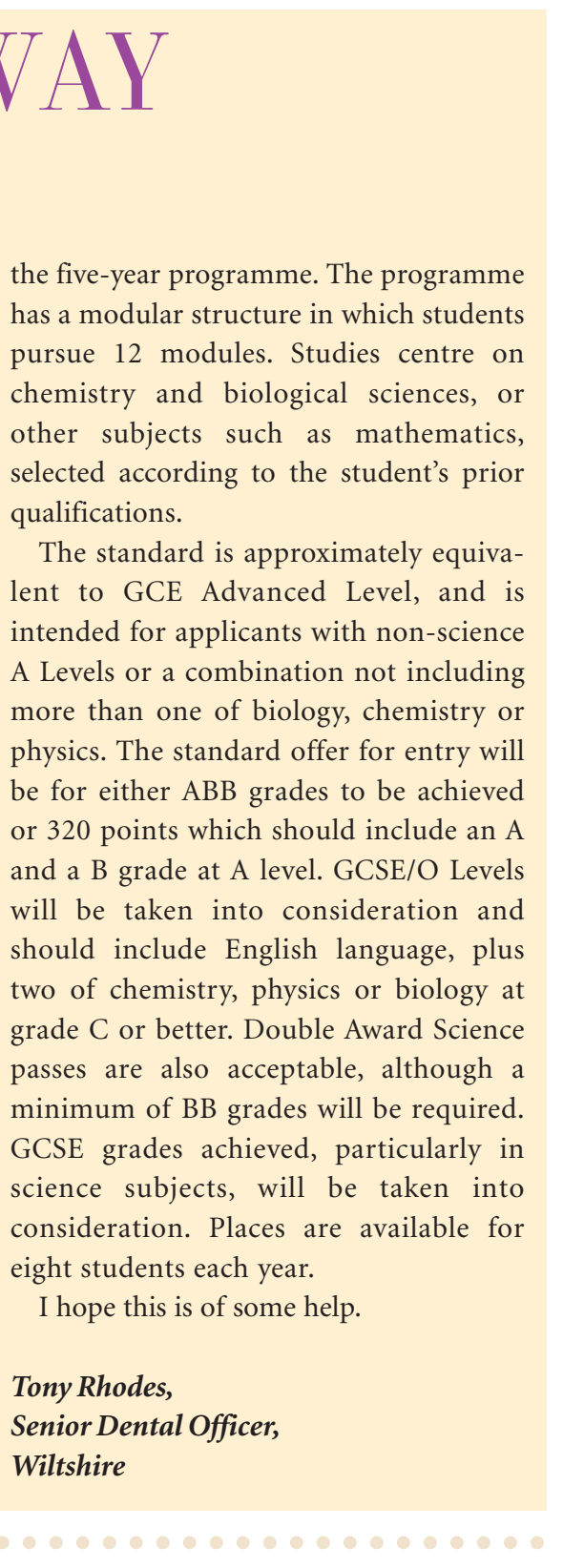

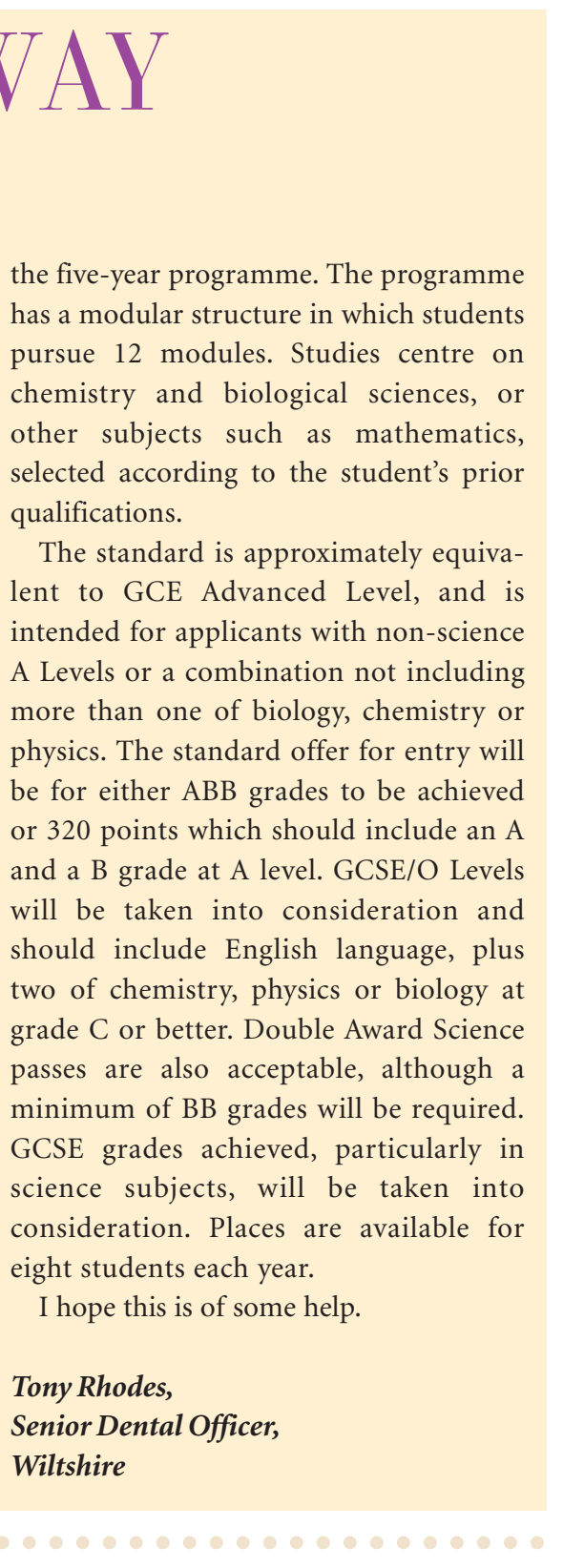

